gebene Temperatur nicht überschritten werden. Das gepulverte Erz entwickelt dabei Dämpfe von Wasser, Schwefel und schwefliger Säure, nebst antimonialischem und arsenikalischem Rauche und wird allmälig heller von Farbe und strengflüssiger. Dieser Process dauert gewöhnlich 2-3 Stunden und ist als beendigt zu betrachten, wenn keine schwefligen, antimonialischen oder arsenikalischen Dämpfe mehr entstehen, und die Farbe des Pulvers nicht mehr heller wird. Sämmtliches Antimon fast ist dann in wasserfreie antimonige Säure übergegangen. Diese wird durch Mahlen und Schlämmen mit Wasser in ein fast unsichtbares Pulver verwandelt und stellt getrocknet ein weisses Piginent dar, welches mit Leinöl oder Firniss abgerieben, als Anstrichfarbe verwendbar ist, auch kann dasselbe in Verbindung mit Zinkoxyd, Bleiweiss, Chromgelb u. s. w. benutzt werden.

(Welche Vortheile die antimonige Säure gegen Bleiweiss und namentlich Zinkweiss gewährt, geht aus dem Aufsaize nicht hervor. B.) (Repert. of Patent Inventions. Octbr. 1861. S. 374.) Bkb.

\title{
Oxalsaures Cerium als Magenmittel
}

Simpson in Edinburg hat ungefähr vor einem Jahre das oxalsaure Cerium gegen Erbrechen der Schwangeren angewendet, seitdem hat man es auch bei anderen Magenleiden versucht. Es bildet ein weisses körniges Pulver, ist geruch- und geschmacklos, unlöslich in Wasser, Alkohol und Aether, leicht löslich jedoch in Schwefelsäure. Lee fand es auch wirksam beim Erbrechen, welches die letzten Monate der Schwangerschaft begleitet, wo Creosot, Blausäure, Eis, das salpetersaure Wismuth etc. vergeblich gebraucht worden waren. Lee erhielt auch sehr günstige Wirkung in 14 Fällen von Dyspepsie. Unter dem Einflusse dieses Mittels kehrte der Appetit eben so rasch zurück, als die Uebelkeit und andere Symptome verschwanden. Diese Schnelligkeit der Wirkung, schon von Simpson angegeben, war in allen Fällen Lee's sehr auffallend. Die Gabe des Mittels ist 5 bis 10 Centigrm. (Arch. génér. 1861.) B. 